\title{
Olimpíadas 2016, discursos em torno das favelas e o atual projeto de reforma urbana do Rio de Janeiro
}

\section{The 2016 Olympics, Discourses around Favelas and the Urban Reform of Rio de Janeiro}

\begin{abstract}
Liv Sovik | Universidade Federal do Rio de Janeiro Formada em letras pela Yale University com doutorado em Comunicação pela USP, é professora associada da Escola de Comunicação, UFRJ. Analisa os embates políticos e culturais implícitos em discursos identitários brasileiros. É autora de Aqui ninguém é branco e organizou Da Diáspora, coletânea de textos do teórico da cultura, Stuart Hall

E-mail: Isovik@gmail.com
\end{abstract}

Camila Calado | Universidade Federal do Rio de Janeiro Doutoranda em Comunicação e Cultura da Escola de Comunicação, UFRJ, com bolsa CNPQ. Mestre pela mesma instituição. E-mail: camilacalado.ufrj@gmail.com

\begin{abstract}
Resumo
O trabalho analisa o marketing da candidatura Rio 2016, Live your passion e os discursos em torno da reforma urbana entendida como "legado" para o Rio de Janeiro dos Jogos Olímpicos de 2016. Argumenta que o discurso legitimador das remoçóes nas favelas começa a ser construído na candidatura com o discurso do legado e, adiante, com o do bom governo da cidade integrada via políticas públicas. Lançando mão da noção foucaultiana de biopoder, conclui que as atuais intervençóes urbanísticas legitimam açóes de segregação social na cidade.
\end{abstract}

Palavras-Chave: Marketing; olimpíadas 2016; remoção de favelas

\begin{abstract}
This article analyses the marketing of Rio de Janeiro's candidacy for the 2016 Olympics and the discourses around urban reform, understood as the games' "legacy" to the city. It argues that discourses legitimising favela clearance began to be constructed during the marketing campaign as a discourse about the legacy, and were later associated with good government of a city integrated by means of suitable public policy. Using Foucault's notion of biopower, it concludes that the current government policy and actions legitimize social segregation.
\end{abstract} Keywords: Marketing; 2016 Olympics; favela clearance 


\section{Escritas sobre a cidade}

Múltiplos são os Rios de Janeiro e múltiplas são as formas de narrá-lo. A escrita da cidade é um relato específico e sensível da forma como o leitor a percebe. Tal visão pode provir de suas experiências, da observação à distância, de seus modos de apropriar-se e de reinventar o espaço urbano, das representaçóes midiáticas, a partir de um olhar que privilegia tais construçóes de sentido em detrimento das experiências cotidianas, e dos imaginários urbanos. A cidade torna-se um texto diante de olhares diversos, mas jamais pode ser compreendida em sua totalidade, de modo que o olhar e a escrita lidam apenas com partes da cidade-texto, são compreensóes parciais, apesar de revestidas da ilusão da totalidade ou da realidade.

Os principais relatos que circulavam em níveis local e internacional sobre o Rio foram levados em consideração no momento de definição das estratégias do marketing da candidatura aos Jogos Olímpicos e Paralímpicos de 2016. Era um momento crucial de investimento simbólico na imagem da cidade, que tornava necessário o reforço dos atributos positivos, o estabelecimento de estratégias para lidar com relatos negativos que colocavam em dúvida as condiçôes do Rio sediar o megaevento esportivo e a projeçáo da imagem futura da cidade.

Nas últimas décadas, dois discursos sobre o Rio alcançaram ampla repercussão internacional: a cidade maravilhosa e a cidade do caos e da desordem. Para além de constituírem-se como opostos, estão imbricados, estabelecem diálogos entre si e com inúmeros relatos midiáticos e do cotidiano da cidade, apresentando elementos de livre circulaçáo entre os mesmos. A favela transita entre os dois discursos, podendo ser compreendida como zona de fluxos discursivos entre a paranoia e o espetáculo, atrelada tanto positiva quanto negativamente à imagem do Rio. A favela tornou-se "um terreno de disputa numa batalha de representaçôes" (JAGUARIBE, 2010, p. 12). Se de um lado havia a imagem da favela cool, comunidade autêntica e pujança cultural a ser explorada positivamente, de outro, fazia-se imprescindível estabelecer estratégias para lidar com a urbe da violência e do narcotráfico e da escassez.

$\mathrm{O}$ artigo propóe refletir sobre a inserção da favela no projeto Rio Olímpico, a partir da descrição analítica do marketing da candidatura, dos discursos sobre a atual reforma urbana, por meio dos projetos UPP, Morar Carioca e Porto Maravilha, e sobre as práticas de remoçóes nas favelas.

\section{A favela no marketing Rio 2016, Live your passion}

Para o estudo do material da campanha Rio 2016, Live your passion, optou-se por uma leitura acurada, guiada pelo propósito de perceber quais narrativas sobre o Rio de Janeiro e sobre a favela foram priorizadas, esquecidas ou renovadas. A leitura dos textos foi guiada pelas fases: identificação dos principais temas presentes ou ausentes; identificação dos padróes de aproximação ou contradição; enquadramento em categorias temáticas; tentativas de explicação das presenças e de decifração dos silenciamentos dos textos. O percurso metodológico foi montado a partir da leitura das técnicas de análise de dados close reading, análise textual e análise de conteúdo categorial.

O processo de construção do Rio como cidade ideal para sediar os Jogos de 2016 recupera os consagrados cartôes-postais, em meio a narrativas 
do cotidiano e de práticas esportivas. A exaltação das paisagens é comum em todos os vídeos analisados (exceçáo do mini doc Barbara), no Dossiê de Candidatura e na Carta Rio 2016. "A natureza não é somente parte do Rio de Janeiro, ela é a própria cidade” (BRASIL, 2009a, p. 86).

São exaltados os símbolos da paixão e da celebração como características da cidade. O slogan Live your passion convida os visitantes estrangeiros a vivenciarem sua paixão pelo esporte, a conhecerem a "paixão do Rio pela vida" (BRASIL, 2009a, p. 38) e a "atmosfera de celebração tipicamente brasileira" (BRASIL, 2009b, p. 8). Uma cidade que canta, vibra, dança e esbanja alegria naturalmente no seu dia a dia, seja através da torcida pelo seu time, no show de Ivete Sangalo, no baile funk, nos sambas dos botequins ou na labuta diária do motorista do bondinho de Santa Tereza, como registram os vídeos Unity, Celebration e Passion.

A categoria da paixão está também interligada aos símbolos da cordialidade, mestiçagem e convivência pacífica com as diferenças culturais. O Rio é representado como cidade ideal para sediar o megaevento marcado por uma infinidade de diálogos culturais, em razão dos diálogos raciais, étnicos e culturais comporem seu cotidiano. A locução de Unity (2009) enfatiza: "unindo o mundo como nunca antes. A paixão irá nos unir" e o presidente Lula reitera, na apresentação em Copenhagen: "povo misturado, povo que gosta de ser misturado. Isso é que faz nossa identidade".

A imagem do país mestiço é reforçada nos vídeos a partir da escolha dos personagens, das protagonistas mulatas de Unity (2009) e Passion (2009) e da presença de diferentes cores e biotipos ao longo das narrativas audiovisuais. A logomarca da campanha, nas palavras de Nuzman, presidente do COB, também revela a "característica de ser acolhedora sem distinção de raça ou cultura, como é o próprio brasileiro". E o slogan Live your passion traduz a "maneira aberta e democrática com que o país recebe e convive com as diferentes culturas, raças, religiôes e comportamentos." (UOL, 2008).

A cordialidade e hospitalidade podem ser entendidas como metáforas para lidar com as questóes raciais e sociais do país. O conceito de "homem cordial" discutido por Holanda (1995) é mais ambivalente que a característica afetiva e hospitaleira, presente no senso comum e difundida pela mídia (SOVIK, 2009). "A lhaneza no trato, a hospitalidade, a generosidade, virtudes tão gabadas por estrangeiros que nos visitam" representam um traço do caráter nacional brasileiro, na medida em que retomam as relaçôes sociais da sociedade agrária e patriarca (HOLANDA, 1995, p. 146). Tais virtudes não representam civilidade, doçura ou boas maneiras. A forma de convívio social do brasileiro, para Holanda (1995), seria o oposto da polidez. A atitude polida seria um disfarce das reais emoçóes e sensibilidade, bem como uma defesa diante da sociedade, uma vez que, provido desta máscara, o indivíduo manteria sua supremacia diante do social.

O marketing abarca as camadas populares, afinal, trata-se de um país que se divulga mestiço e acolhedor, um governo federal que se promovia como beneficiador de todos e uma gestão municipal que projetava a integração da cidade. No vídeo Passion, observa-se um guarda de trânsito negro soando seu apito; um pescador negro que canta a cidade, enquanto prepara sua rede de pesca; um gari negro que dança, enquanto varre a cidade; um motorista de 
ônibus branco que segue cantando a maravilha do Rio rumo à Santa Tereza; e um jardineiro de estádio de futebol que assobia no ritmo da cidade maravilhosa. O Rio seria o local de pessoas trabalhadoras e guerreiras, que mesmo diante das dificuldades, não esquecem o sorriso e brindam a cidade.

Destaca-se a escolha da atleta Bárbara Leôncio como protagonista do vídeo Unity e do mini doc Barbara. O primeiro, claramente construído em torno do discurso da convivência pacífica dos brasileiros com as diferenças, é protagonizado pela atleta que alcançou vitórias esportivas, mesmo vindo de um contexto carente de infraestrutura, como registra Barbara. Moradora de Curicica, foi campeã de atletismo de menores em 2007 e entrou para a história do esporte nacional como a primeira brasileira a conquistar título mundial em prova feminina de atletismo. Leôncio participou da cerimônia de eleição da cidade sede ao lado do então presidente Lula e recebeu com Nuzman (COB) o diploma pela candidatura do Rio das mãos de Jacques Rogge, presidente COI. Ganhou destaque na imprensa pela emoção despertada em Lula e por ele narrada: "Quando eu vi aquela menina, a Bárbara, na mesa ao meu lado, com lágrimas nos olhos, e eu fui falar, eu estava emocionado, eu estava com um orgulho imenso de estar defendendo o Brasil” (LULA; NUZMAN, 2009). Recebeu a alcunha de o "principal símbolo do Rio 2016" e "símbolo da vitória" (UOL, 2009), sendo assunto também da mídia internacional.

A participação de Leôncio contribuiu para reforçar a importância dos Jogos de 2016 para os milhóes de jovens brasileiros talentosos, mas que enfrentam dificuldades para realizar o treinamento esportivo. No plano discursivo, a superação já marcaria a história do país, como ressaltou Lula, e a expansão do movimento olímpico seria a oportunidade de unir o espírito guerreiro às melhores condiçóes de treinamento, oriundas das transformaçóes que seriam implementadas na cidade, uma vez eleita sede olímpica.

Neste cenário, construiu-se um conceito que permeou toda a campanha: o legado dos Jogos. $\mathrm{O}$ conceito Rio da renovaçáo abarca açóes de transformação e de inserçáo social por meio de projetos de melhorias do transporte público, de segurança, de preservação ambiental, de infraestrutura, de geração de empregos. "Serão os Jogos da celebração e da transformação, os Jogos da paixão e da determinação". (BRASIL, 2009a, p. 10). "Os Jogos serão fundamentais para antecipar a realização de aspiraçóes de longo prazo do Rio de Janeiro, aprimorando o tecido social, físico e ambiental da cidade, um processo que já está em andamento graças à própria candidatura aos Jogos de 2016” (BRASIL, 2009a, p.18).

O conceito do legado contempla ganhos sociais oriundos da transformação das instalaçôes esportivas e da infraestrutura visando a integração de jovens e das comunidades carentes (BRASIL, 2009a). No caso do Centro Olímpico de Treinamento (COT), é prevista a utilização para a preparação dos atletas olímpicos e o apoio a "programas organizados nas comunidades vizinhas, para promover a participação esportiva e hábitos de vida saudável, destinados à população carente e aos jovens". (BRASIL, 2009a, p. 22). Destaca-se, todavia, que as tabelas de uso das instalaçóes esportivas pós-Jogos revelam apenas dois 
casos, de um total de 63 instalaçôes, em que está previsto o uso pós-jogo para fins comunitários (BRASIL, 2009b).

Segundo o Dossiê de candidatura, a comunidade participaria da supervisão do legado do megaevento podendo acompanhar a adequação do "alinhamento completo do Plano Mestre dos Jogos aos objetivos de longo prazo da cidade" (BRASIL, 2009a, p. 20). Em diferentes trechos, reforça-se a proposta de inserir toda a cidade no projeto dos Jogos, beneficiando as comunidades também através de programas de licenciamento e de incentivo à prática esportiva (BRASIL, 2009a).

Em relação à tal prática, são citados o Programa Segundo Tempo, com a proposta de promover o acesso de 3 milhóes de crianças de escolas públicas ao esporte; o Mais Educação, com a previsão de investimento em infraestruturas esportivas de escolas públicas; o Rio Olimpico, com o objetivo de aumentar os investimentos em programas e infraestrutura esportiva, possibilitando "o acesso das comunidades às instalaçóes dos Jogos” (BRASIL, 2009a, p.24). Aqui, tem-se a primeira presença explícita do território físico da favela no material da candidatura, a partir da fotografia de garotos jogando vôlei em quadra de uma comunidade. Não há legenda ou texto que faça referência específica à fotografia, mas a análise conduz ao entendimento de que se trata do projeto social da Escola de Vôlei Bernardinho, desenvolvido na Comunidade Tavares Barros.

Adiante, no tópico Riscos naturais em potencial, aborda-se a histórica ocupação desordenada dos morros e encostas. "A expansão urbana em muitos casos invadiu o ecossistema das planícies e das encostas, aumentando os riscos de deslizamentos, de assoreamento dos sistemas de água, e de inundaçóes causadas pelas chuvas de verão". (BRASIL, 2009a, p. 86). Tal aspecto que aparece pontualmente no Dossiê é adiante adotado como argumento para remoçóes de favelas: o argumento do risco ambiental e, por conseguinte, do risco de vida para o morador.

Trecho referente à construção do COT expóe que a "transferência das acomodações ilegais nas margens da Lagoa de Jacarepaguá para um novo local e a integraçáo de um parque ajudarão a renovação e o acesso do público nesta região protegida”. (BRASIL, 2009a, p. 100). As desapropriaçóes são mencionadas como aspecto positivo para a cidade através de um segundo argumento: as instalaçôes do megaevento. Como se vê, já no projeto de candidatura começam a ser delineados os primeiros discursos em torno das remoçóes. As vantagens dos Jogos abrangeriam, consoante o material, até mesmo aqueles que seriam desapropriados de suas casas, pois "serão oferecidas casas populares, o que irá melhorar consideravelmente a sua qualidade de vida” (BRASIL, 2009b, p. 144).

Outra presença da favela se dá através do tema da segurança. "A redução da criminalidade foi e continua sendo um dos principais objetivos das autoridades policiais no Rio de Janeiro. Iniciativas de combate ao crime são tomadas em conjunto com estratégias de redução da criminalidade nas comunidades, como o PRONASCI" (BRASIL, 2009c, p.28). Recupera a experiência do Rio na manutenção da paz e na redução da criminalidade durante grandes eventos, aspecto contemplado também na Avaliação do COI (2009), e evidencia que os programas de gerenciamento de crime serão baseados em avaliaçóes detalhadas das instalaçóes dos Jogos e de áreas de possível visitação da família olímpica. "As áreas de maior 
incidência de crimes serão identificadas e planos de redução da criminalidade específicos para essas áreas serão traçados". (BRASIL, 2009c, p. 28).

O relatório de Avaliação do COI (2009) destaca os avanços recentes na segurança pública e nas reduçóes de crime na cidade, através de uma mudança de abordagem, incluindo programas de policiamento nas comunidades e programas sociais com atividades esportivas que promovam a integração de disadvantaged areas of Rio (I.O.C., 2009, p. 58), reduzam o crime e aumentem a participação de jovens no esporte.

Como se trata de uma representação direcionada ao público externo, o marketing Rio 2016 se apropria do discurso do legado, amplamente valorizado pelo COI, como estratégia de promoção positiva da cidade, argumentando que as Olimpíadas iriam solucionar os problemas internos do Rio. Se os Jogos têm como uma de suas características o legado que deixará para as cidades sede, o Rio torna-se candidata relevante por ter problemas sociais a serem resolvidos.

No material, verifica-se o reforço dos estereótipos da favela como lugar de carência, ocupaçáo desordenada e território do crime ou, dito de outro modo, a associação desse território aos mitos da marginalidade - conjunto de estereótipos da favela como estigma da desorganização social, da desordem urbana e da violência (PERLMAN, 2002). Tais práticas representacionais inscrevem maneiras limitadas de olhar para tais territórios e permitem que a história da cidade seja contada a partir de um olhar específico que coloca favelados como síntese dos problemas da cidade. Representaçóes contemporâneas sobre o potencial turístico, criativo e gerador de cultura da favela são reduzidas pelas usuais estereotipias.

\section{A favela nas reformas urbanas do Rio de Janeiro}

Ao longo da história, a favela aparece como sinônimo de carência, de irregularidade, de empecilho ao ordenamento público, local de "vagabundos e criminosos", como inimigo da cidade maravilhosa e a síntese dos problemas da cidade. Zaluar e Alvito (2006, p. 9) evidenciam que, apenas três anos após o Ministério de Guerra ter permitido a ocupação do Morro da Favela por militares da Revolta de Canudos, este passou a ser "percebido pelas autoridades policiais como um 'foco de desertores, ladróes e praças do Exército"” e ainda como um problema sanitário, policial e de moralidade pública, conforme carta de 1900 do delegado Enéas Galvão. A favela já nasce como problema.

A Reforma Passos (gestão 1902-1906) foi o primeiro projeto de "intervenção estatal maciça sobre o urbano, reorganizado agora sob novas bases econômicas e ideológicas, que não mais condiziam com a presença de pobres na área mais valorizada da cidade" (ABREU, 2008, p. 63). Em nome do progresso, da estética e dos problemas de higiene, realizou-se a demolição de casas da população pobre, a desapropriação de prédios além do número necessário para as obras - a prefeitura visava vender após a valorização imobiliária -, a proibição da mendicância e da venda de produtos pelos ambulantes. A cidade passou ainda por um processo de higienizaçáo com as propostas de Oswaldo Cruz e a implantação da Lei da Vacina Obrigatória, exemplo de poder que usa sua dimensão bios para legitimação das ações de discriminação. 
As intervençóes urbanísticas de Passos servem como inspiração para o prefeito Paes, que menciona o desejo de ser lembrado como um urbanista à la Pereira Passos. Os grupos de resistência, todavia, aproximam os prefeitos pelas semelhanças nas práticas de deslocamentos forçados. A este respeito, Abreu (2008) atenta que o período Passos é um exemplo de como a - suposta - resolução das contradiçóes geram novas contradições. Diante da expulsão dos cortiços, os morros do centro, até então pouco habitados, passaram a ser rapidamente ocupados, pois se tornaram a única alternativa de habitação da população pobre que necessitava residir próximo ao trabalho.

Valladares (2000, p. 14) assinala que é neste período que se dá a problematização da favela, mesmo diante da não generalização do processo de favelização pela cidade. A ideia da favela como problema deve-se enfaticamente ao saber de médicos higienistas, que a percebiam como deficiência do "corpo urbano", "patologia social que precisava ser combatida", e de engenheiros que defendiam a resoluçáo dos males "do organismo enfermo - a cidade - imprimindo-lhe uma direçâo ordenadora".

A partir de Passos, inúmeras outras ações de realocação dos pobres na cidade foram efetuadas por diversas gestóes governamentais. O período subsequente que se destacou foi a administração de Carlos Sampaio (1920-1922), que tinha como meta a preparação do Rio para as comemoraçóes do Centenário da Independência do Brasil, em 1922. Habitaçôes proletárias foram extintas e populaçóes pobres, situadas nas regióes que seriam repaginadas, foram removidas. Aproveitava-se a situação política favorável, devido à proximidade das comemoraçôes do centenário para o afastamento dos pobres, situação semelhante aos atuais preparativos da cidade para as Olimpíadas. A postura adotada em relaçáo à população pobre culminou no apelido de prefeito "bota-abaixo", título recentemente recuperado pela resistência para fazer referência à gestão de Paes.

Nos anos 20, destaca-se a atuação de João Augusto de Mattos Pimenta, apresentado ora como médico sanitarista, ora como engenheiro e jornalista. Entre 1926-1927, ele empreendeu a primeira grande campanha contra a favela, denunciando-a à imprensa e aos poderes públicos como um problema para o projeto de remodelação do Rio. $\mathrm{O}$ argumento mesclava os discursos médico-higienista, reformismo progressista e o pensamento urbanístico em ascensão, inserindo ainda noçôes estéticas e arquitetônicas. Defendia uma barreira profilática contra a "infestação avassaladora das lindas montanhas do Rio de Janeiro" e contra a sujeira e a miséria que enchia "preferentemente os bairros mais novos e onde a natureza foi mais prodiga de bellezas." (MATTOS PIMENTA, 1926, p. X apud VALLADARES, 2000, p. 15) Propunha a construção de casas populares, a contenção da expansão das favelas, com impedimento de novas construçóes, e a fiscalizaçáo da prefeitura.

Este "importante ator social na história da favela", como define Valladares (2000, p. 16), pareceu influenciar as percepçóes e propostas de Alfred Agache. $\mathrm{O}$ urbanista francês retomou a imagem da lepra vinculada à favela, estabelecida por Mattos Pimenta, e construiu um discurso baseado em parâmetros higienistas, estéticos e urbanistas. Agache não se limitou, todavia, a apenas tratar a favela como um problema, mas buscou entender as causas, percebendo que 
elementos exteriores à pobreza explicavam o fenômeno. Propunha a construção de habitaçóes para os moradores das favelas, expondo que a simples expulsão implicaria na instalação dos mesmos em outras habitaçôes com condiçóes similares. Recomendava que os poderes públicos se esforçassem para impedir a construção estável e definitiva das favelas.

Os mitos da marginalidade contribuem para a legitimação de políticas e justificativa das remoçóes (PERLMAN, 2002). A autora defende que os moradores de favelas não são marginais dos pontos de vista econômico, social, político e cultural; estão integrados à sociedade, mas de modo desfavorável: são explorados, estigmatizados e marginalizados. As remoçóes e, por conseguinte, a realocação em locais distantes contribuem para o afastamento dos serviços urbanos e para desestabilizar os modos de integraçáo da favela à dita cidade formal. As práticas remocionistas criam, assim, a população marginalizada que se pretendia eliminar.

A remoção da favela não é apenas reflexo dos mitos, mas constitui "nítida expressão do fenômeno geral da ideologia da marginalidade, que age como uma força material no sentido de diminuir o poder de barganha de certos setores populares”. (PERLMAN, 2002, p. 236). Facilita a aceitação e justifica a "implementação de qualquer política oficial que se refira direta ou indiretamente aos setores populares da sociedade urbana” (p. 292).

\section{O projeto atual do Novo Rio}

Para a implementação de um projeto de transformação urbana, é necessário a percepção de crise aguda, "a negociação entre os atores urbanos, públicos e privados, e a geração de liderança local (política e cívica)" (CASTELLS, BORJA, 1996, p. 156), a vontade conjunta e o consenso público para o desenvolvimento da cidade. No Rio de Janeiro, assim como em Barcelona, o megaevento olímpico tem sido legitimado a partir dos discursos de superação da crise, do desenvolvimento da cidade e do legado urbano. Com isso, consegue-se silenciar parte da discussão política sobre assuntos ligados ao projeto olímpico e adotar estratégias excepcionais de gestáo, em nome do cronograma a ser cumprido. Os dois casos exemplificam a utilização de um megaevento como catalisador da transformação urbana. Entretanto, enquanto em Barcelona, as Olimpíadas foram aproveitadas para a catalização de projetos inseridos no plano de reestruturação da cidade, no Rio, "o planejamento da cidade e a prioridade dos investimentos públicos é que passam a ser determinados pelo projeto do evento". (OLIVEIRA, GAFFNEY, 2010).

A partir da seleção oficial do Rio como candidata à sede dos Jogos de 2016, em junho de 2008, as políticas públicas desenvolvidas na cidade passaram a estar vinculadas ao seu projeto de candidatura (BRASIL, 2009b). O combate à violência e a manutenção da ordem apareceram como principais linhas de ação dos governos municipal e estadual, afetando grupos mais pobres. Em novembro, foi implantada a primeira Unidade de Polícia Pacificadora, na favela Santa Marta, Zona Sul da cidade. Segundo o discurso oficial, o novo modelo de Segurança Pública teria como proposta recuperar os territórios dominados há décadas por traficantes e milicianos, levar a paz e a inclusão social para as comunidades (ASCOM SEGEG, 2012). 
A segurança pública aparece como uma das questôes fundamentais do processo de reinvenção da cidade para os Jogos 2016, afinal, diante do impacto da violência no imaginário internacional e da produção do medo no imaginário nacional, fazia-se urgente o estabelecimento de estratégias para o enfrentamento da questão. Tais estratégias tornavam-se mais urgentes no momento em que eventos violentos envolvendo traficantes de favelas - um helicóptero da polícia foi derrubado e dez ônibus foram queimados - repercutiram internacionalmente, apenas quinze dias após a vitória à sede olímpica, suscitando preocupaçóes sobre as condiçóes da cidade sediar o megaevento. A resposta do poder público foi deslanchar as UPPs por diversas favelas.

No início de 2009, o Comitê Rio 2016 entregou ao COI o Dossiê de Candidatura (BRASIL, 2009a, p. 36), que abordava a transformação da cidade como um dos quatro pilares dos Jogos. A transformação compreenderia, dentre outros, a revitalização da Zona Portuária e "importantes obras no setor de habitação, transporte e serviços públicos [que] darão uma nova vida ao porto", (BRASIL, 2009a, p. 36). Este é o discurso principal do projeto Porto Maravilha que, dentre obras de cunho turístico, propóe a recuperaçáo completa da infraestrutura urbana, de transportes e do meio ambiente da regiáo, melhorias habitacionais, a reurbanização do Morro da Conceição, a instalação de uma UPP no Morro da Providência e a ampliação do túnel ferroviário sob a referida comunidade para receber tráfego de automóveis (RIO DE JANEIRO, 2009).

No mesmo ano, o governo estadual, com o apoio municipal, apresentou o projeto de construçáo de muros em favelas com a justificativa de prevenir a expansão. O início das obras, com custo total de 40 milhóes de reais, ocorreu novamente na favela Santa Marta, com a justificativa de conter a expansão para proteção da floresta nativa restante. Simultaneamente à construção dos muros de 3 metros de altura, foram divulgadas as remoçóes de inúmeras famílias, 415 apenas na Rocinha (ZAHAR, 2009).

Em 2010, foi lançado o Morar Carioca, projeto integrante do Plano de Legado Urbano dos Jogos, que visa "promover a inclusão social, através da integração urbana e social completa e definitiva de todas as favelas do Rio até o ano de 2020" (RIO DE JANEIRO, 2012a), acabando, assim, com a Cidade Partida (CIDADE OLÍMPICA, 2011). Disso deriva a proposta de urbanizar as favelas, a partir de melhorias de infraestrutura, habitação, serviços, sustentabilidade ambiental, moradia e acessibilidade. $\mathrm{O}$ projeto é defendido como um avanço para a cidade, que permitiria "criar a cultura de que comunidade urbanizada faz parte da cidade", nos termos do prefeito. (RIO DE JANEIRO, 2011).

O principal discurso que começa a circular em torno desses projetos e da reconfiguraçáo arquitetônica e simbólica das favelas por eles proposta é a integração da cidade, compreendida como uma atualização do usual slogan cidade maravilhosa que, agora, abarca a remodelaçáo das favelas. Discursivamente, as mudanças implementadas representariam um avanço para a cidade, trazendo benefícios sociais e culminando na superação da dicotomia morro/asfalto. Para além do discurso oficial, entretanto, tem-se observado realidades outras. 
Três meses após a eleição do Rio como sede olímpica, a prefeitura divulgou uma lista de 119 comunidades marcadas para remoção até 2012, em virtude de estarem localizadas em áreas de risco, de proteção ambiental ou destinadas a logradouros públicos. Mais de um terço das favelas, destacam Gaffney e Melo (2012), estão localizadas na Barra da Tijuca e em Jacarepaguá, "o coração dos Jogos" (BRASIL, 2009a).

As remoçóes, que iniciam com o Choque de Ordem do prefeito Paes, também têm episódios relacionados à instalação dos prédios das UPPs, a exemplo da Unidade no Morro do Cantagalo que culminou na retirada de 26 famílias de suas casas (GRANJA, 2010). O projeto também foi alvo de denúncias sobre violência e abuso dos policiais.

Em relação ao Porto Maravilha, as críticas abrangem a falta de transparência na divulgação de informaçôes, a valorização imobiliária da área, que gera movimentos especulativos, e a tendência à gentrificação, ao deslocamento indireto de moradores locais, em razão do aumento do custo de vida. Para De Melo e Gaffney (2012), a escolha para a execução do projeto na região portuária está relacionada ao tipo de estrutura fundiária da área, vez que $75 \%$ dos terrenos pertencem ao Estado, o que parece um facilitador para as negociaçóes com os moradores, para as desapropriaçóes e para a redução da resistência.

Sobre as críticas ao Morar Carioca, pode-se citar o caso da Providência. A comunidade questionava a opçáo pela construção de teleféricos, diante de necessidades mais urgentes, reivindicava uma maior participação na elaboração e implementação do projeto de reurbanização, o reassentamento na comunidade, posto que o projeto previa o desadensamento de áreas de intensa ocupação ou percebidas como insalubres, e o reassentamento de moradores de regiōes de risco em moradias do Minha Casa, Minha Vida (RIO DE JANEIRO, 2012b).

\section{Cidade integrada pra quem?}

O cenário oficial do Rio pré-olímpico é marcado por dois principais movimentos discursivos em relação à favela. De um lado, observa-se a favela como parte do projeto, a construção da mesma como marca da cidade e a sua reconfiguração arquitetônica e simbólica. Encontra-se, aqui, o projeto das UPPs, o Porto Maravilha e o Morar Carioca. Paralelo a tais fluxos de interação com as comunidades, entretanto, há percepçóes da favela como território de desvalorização do projeto Novo Rio, como empecilho ao projeto/progresso, sendo eleitas para a remoção.

Em torno dessas ações, circula o discurso da remoção para o bem do morador da favela, para a promoção de melhores condiçóes habitacionais e de uma vida mais digna. Discursivamente, as autoridades governamentais, reforçadas pelo saber de arquitetos, urbanistas e engenheiros, procuram superar o tabu histórico da remoção como algo negativo, ressignificá-la positivamente e reconfigurá-la como ação a favor da vida do favelado.

As justificativas de erradicação das favelas pelo discurso da higiene e do embelezamento, por se tratarem de "aberraçóes" que não deveriam constar no mapa da cidade, são substituídas pelo discurso de prover melhores condiçóes de vida. $\mathrm{O}$ interesse do poder público, no plano discursivo, não seria excluir 
tais territórios, mas integrá-los à cidade. De prática autoritária, a remoção se transformaria em ação democrática, em algo benéfico para os moradores. Para Magalhães (2012), a mobilização de um repertório discursivo que justifica e legitima a prática remocionista é sintomático da tentativa de reconstruir a remoção como um problema público. A declaração de Paes é denunciativa:

[...] as mudanças farão do Rio uma melhor cidade para se morar e trabalhar, mais igualitária e mais gentil com sua população. Você vê as favelas. Qual é a razão de alguém ir parar no alto de um morro, em um lugar perigoso, em uma casa horrivel e pequena? Isso acontece porque se ele for viver em uma casa melhor um pouco mais afastada, ele vai precisar de três ou quatro horas (de transporte) para chegar lá [...] Quando falamos que vamos aumentar (a capacidade do transporte de massa) de 15\% da população para 60\%, o que estamos dizendo é que haverá uma boa alternativa para que pessoas pobres não precisem morar ao lado do trabalho, eles podem morar um pouco mais longe, em lugares melhores e mais seguros, e chegar rapidamente ao trabalho. [...] O que está sendo feito na cidade é principalmente para o carioca médio, o carioca mais pobre. (PAES, DATA, p. apud CARNEIRO, 2012, p. X).

A ambivalência de tais discursos se revela à luz do biopoder (FOUCAULT, 2005), tendo em vista que o deixar morrer expóe moradores à morte, a riscos e à exclusão, enquanto políticas que fazem viver são orientadas a faixas mais ricas da populaçáo. Favorece-se a vida da cidade em detrimento do morro, lembrando aqui as noçóes de Foucault (2005) de que o assassínio pode ser direto ou indireto, ou seja, a periferização e a gentrificação são ações do lado da morte. Essa é a situação verificada ao longo da história das transformaçóes urbanas do Rio e que parece se repetir na atual remodelação da cidade.

Magalhães (2012) argumenta que, a partir de 2009, o cenário estaria favorável para a implementação de uma política oficial de remoção. A ideia de caos e desordem urbana associada ao crescimento das favelas se aliaria à preparação da cidade para sediar os megaeventos esportivos. Tais argumentos se acoplam ao risco de vida, à proteçáo ambiental e ao legado para a cidade num processo de reconfiguração das remoçóes como açáo a favor da vida dos favelados. Observa-se, todavia, a utilização da dimensão bios para renovação do poder sobre a vida dos favelados, para atualizar mecanismos de gestáo e controle.

$\mathrm{Na}$ prática, o tratamento conferido às favelas é muito semelhante ao histórico deixar morrer. Pessoas são expulsas de suas casas, sem o direito ao diálogo prévio sobre as mudanças a serem realizadas, sem acesso ao projeto previsto para a regiáo e sem participação na elaboração do mesmo, às vezes até sem informação antecipada sobre o prazo para desocupação e sofrendo ameaças para que não entrem com ação judicial e obedeçam aos funcionários da prefeitura. Em suma, sáo retiradas violentamente de suas moradias, têm seus direitos de cidadáos desrespeitados.

A alegação das autoridades governamentais de que a reforma urbana e as mudanças implementadas nas favelas favoreceriam as camadas populares pode ser compreendida a partir do discurso populista ou do governo atento ao bom funcionamento da cidade. Ou a partir da difundida técnica da grande mentira de Goebbels: uma mentira repetida mil vezes torna-se verdade. 


\section{Referências bibliográficas}

ABREU, Maurício de Almeida. Evolução urbana do Rio de Janeiro. Rio de Janeiro: IPP, 2008.

ASCOM SEGEG. - Sobre a UPP. Conceito UPP: a polícia da paz. UPP. Disponível em: http://upprj.com/wp/?page_id=20. Acesso: 08 jun. 2012

BRASIL. Dossiê de Candidatura do Rio de Janeiro à sede dos jogos olímpicos e paraolímpicos de 2016. Brasília: Comitê Rio 2016, 2009a. Disponível em: http://www.rio2016.org.br/sumarioexecutivo/sumario/ptes/Por Volume/Volume_1_ptes.pdf. Acesso em: 1 mar. 2010.

. Dossiê de Candidatura do Rio de Janeiro à sede dos jogos olímpicos e paraolimpicos de 2016. Brasília: Comitê Rio 2016, 2009b. Disponível em: http://www.rio2016.org.br/sumarioexecutivo/sumario/ptes/Por Volume/Volume_2_ptes.pdf. Acesso em: 1 mar. 2010.

. Dossiê de Candidatura do Rio de Janeiro à sede dos jogos olimpicos e paraolímpicos de 2016. Brasília: Comitê Rio 2016, 2009c. Disponível em: http://www.rio2016.org.br/sumarioexecutivo/sumario/ptes/Por Volume/Volume_3_ptes.pdf. Acesso em: 1 mar. 2010.

- Caderno de Legado Brasil. Brasília: Comitê de Gestão das Açóes Governamentais Federais para a Candidatura Rio 2016, 2009 e.

CARNEIRO, Júlia Dias. Olimpiada é 'desculpa fantástica' para mudar o Rio, diz prefeito. BBC. 9 mar. 2012

Disponível em: http://www.bbc.co.uk/portuguese/noticias/2012/03/120308_ eduardo_paes_entrevista_jc.shtml. Acesso em: 10 nov. 2012

CASTELLS, Manuel; BORJA, Jordi. As cidades como atores politicos. Novos Estudos, n. 45, jul. 1996. Disponível em: http://www.novosestudos.com.br/v1/files/uploads/contents/79/20080626_as_cidades_como_ atores.pdf. Acesso em: 17 set 2011.f

FOUCAULT, Michel. Aula de 17 de março de 1976. In: Em Defesa da Sociedade. São Paulo: Martins Fontes, 2005.

GRANJA, Patrick. 'Choque de ordem' póe dezenas de trabalhadores no olho da rua. A Nova Democracia, n 64, abr 2010. Disponível em: http://www.anovademocracia.com.br/no-64/2764-choque-de-ordem-poe-dezenas-de-trabalhadores-no-olho-da-rua-. Acesso em 15 jan 2012.

HOLANDA, Sérgio Buarque de. Raizes do Brasil. São Paulo: Companhia das Letras, 1995.

I.O.C. Report of the 2016 IOC Evaluation Commission - Games of the XXXI Olympiad. 2009. Disponível em: http://www.olympic.org/ Documents/Reports/EN/en_report_1469.pdf. Acesso: 10 ago. 2010.

JAGUARIBE, Beatriz. Ficçóes do real: notas sobre as estéticas do realismo e pedagogias do olhar na América Latina contemporânea. Ciberlegenda, 
Niterói, n. 23, p. 6-14, 2010. Disponível em: http://www.uff.br/ciberlegenda/ojs/index.php/revista/article/view/148/43 Acesso: 07 jul. 2011.

MAGALHÃES, Alexandre. A gramática da ordem na cidade: a reatualização da remoção de favelas no Rio de Janeiro. E-metropolis: Revista eletrônica de estudos urbanos e regionais, Rio de Janeiro, ano 3, n. 8, mar. 2012. Disponível em: http://www.emetropolis. net/index.php?option=com_edicoes\&task=artigos\&id=23\&lang=pt. Acesso: 16 jun. 2012.

MELO, Erick Silva Omena de; GAFFNEY, Christopher. Mega-eventos esportivos no Brasil: uma perspectiva sobre futuras transformaçôes e confitos urbanos. Academia.edu, 10 jul 2012. Disponível em: http://www. academia.edu/648607/Mega-eventos_esportivos_para_quem. Acesso: $18 \mathrm{dez} 2011$.

MORAR Carioca vai urbanizar todas as comunidades até 2020. Portal da Prefeitura do Rio de Janeiro. Disponível em: http://www. rio.rj.gov.br/web/smh/exibeconteudo?article-id=988601. Acesso: 25 jul. 2011.

OLIVEIRA, Nelma Gusmão de; GAFFNEY, Christopher Thomas. Rio de Janeiro e Barcelona: os limites do paradigma olimpico. Revista Bibliográfica de Geografía y Ciencias Sociales, Barcelona, vol. XV, n 895, nov 2010. Disponível em: http://www.ub.edu/geocrit/b3w-895/ b3w-895-17.htm\#_edn6. Acesso: 17 set 2011.

PERLMAN, Janice E. O mito da marginalidade: favelas e políticas no Rio de Janeiro. São Paulo: Paz e Terra, 2002.

RIO DE JANEIRO. Projeto Porto Maravilha. Prefeitura Municipal do Rio de Janeiro, 2009.

- Conheça o Programa. Portal da Prefeitura do Rio de Janeiro. Rio de Janeiro, 2012a. Disponível em: http://www.rio.rj.gov.br/web/ smh/exibeconteudo?article-id=1451251. Acesso:19 out 2012.

- Habitação Morro da Providência. Portal da Prefeitura do Rio de Janeiro. Rio de Janeiro, 2012b. Disponível em: http://www. rio.rj.gov.br/web/smh/exibeconteudo?article-id=2591642. Acesso: 19 out 2012.

SOVIK, Liv. Aqui ninguém é branco. Rio de Janeiro: Aeroplano, 2009.

ZAHAR, André. Muro na favela Rocinha vai remover 415 famílias no Rio. Folha de São Paulo, 14 abr 2009c. Disponível em: http://www1. folha.uol.com.br/folha/cotidiano/ult95u550240.shtml. Acesso: 23 set 2011 .

ZALUAR, Alba; ALVITO, Marcos (org). Um século de Favela. Rio de Janeiro: FGV, 2006. 


\section{Vídeos}

BARBARA. Produzido por O2 Filmes. Postado por AroundTheRings, 5 out. 2009. 1 Vídeo (00:42 min). Disponível em: http://www.youtube. com/watch?v=x81f_7YFaSQ. Acesso: 10 jul. 2011.

CELEBRATION. Postado por gilbertogilmusic, 2 out. 2009. 1 Vídeo (2:18 min). Disponível: http://www.youtube.com/watch\#! $v=n N s P 7 U I Y-$ -qs\&feature=fvw Acesso: 01 mar. 2010.

LULA; NUZMAN, 2009. Lula se emociona e fala sobre Jogos Olímpicos no Brasil após vitória - 2016. Postado por RangelBastos, 02 out. 2009. 1 vídeo (08:14min). Disponível: http://www.youtube.com/ watch?v=xwhwqzgpcky Acesso: 5 abr. 2010.

PASSION. Produzido por O2 Filmes. Postado por VisitRio, 1 jul. 2009. 1 Vídeo (2:24 min). Disponível: http://www.youtube.com/ watch?v=Z00jjc-WtZI Acesso: 01 mar. 2010.

UNITY. Produzido por O2 Filmes. Postado por gabrielvip2, 2 out. 2009. 1 Vídeo (03:27 min). Disponível: http://www.youtube.com/watch?v=_ XhlMZxlxHc Acesso: 01 mar. 2010. 